\title{
Cacau “Jaca” Resistente a Ceratocystis fimbriata na Região Cacaueira da Bahia, Brasil
}

\author{
Stela Dalva V. M. Silva, Márcia Cristina Paim \& Wildson M. Castro \\ CEPLAC/CEPEC/SEFIT, Cx. Postal 07, CEP 45600-970, Itabuna-BA, e-mail: stela@ceplac.gov.br
}

(Aceito para publicação em 08/07/2004)

Autor para correspondência: Stela Dalva V. M. Silva

SILVA, S.D.V.M., PAIM, M.C. \& CASTRO, W.M. Cacau “Jaca” Resistente a Ceratocystis fimbriata na Região Cacaueira da Bahia, Brasil. Fitopatologia Brasileira 29:538-540. 2004.

\section{RESUMO}

Cento quarenta e quatro genótipos de cacaueiros (Theobroma cacao) testados “in vitro", apresentaram-se suscetíveis a altamente suscetíveis ao isolado 2591 de Ceratocystis fimbriata na Bahia. A variedade conhecida como cacau “Jaca” foi o material genético que apresentou maior resistência ao patógeno entre todos os materias testados.

Palavras-chave adicionais: resistência, metodologia, Ceratocystis fimbriata, Theobroma cacao.

\begin{abstract}
Resistance of cacao "Jaca” to Ceratocystis fimbriata in the cacao growing region of Bahia, Brazil

One hundred and forty four cacao (Theobroma cacao) genotypes testified “in vitro", showed susceptibility to high

susceptibility to the isolate 2591 of Ceratocystis fimbriata in Bahia. The variety known, as cacao "Jaca” was the more genetic material that showed resistance to the pathogen among all the materials tested.
\end{abstract}

A doença murcha-de-Ceratocystis do cacaueiro (Theobroma cacao L.) causada pelo fungo Ceratocystis fimbriata Ellis \& Halsted foi identificada por Rorer, em 1918, pela primeira vez no Equador (Rorer, 1918). Até 1950 esta doença era conhecida somente no Equador, causando cancros associados com ferimentos nos troncos, murcha de chupões e podridão nos frutos (Hardy, 1960). A partir desta data, a doença foi detectada em forma epidêmica em países das Américas do Sul, Central e nas ilhas de Haiti e Trinidad, causando danos no cultivo do cacaueiro. Em 1978 foi constatada no Brasil, em Rondônia (Bastos \& Evans, 1978) e, mais recentemente, em 1997 e 1998, em enxertos e cacaueiros adultos na região sul da Bahia (Bezerra, 1997; Bezerra et al., 1998). Desde a sua constatação nesta região, a doença tem ocasionado perdas significativas nas plantações já seriamente comprometidas com a doença vassoura-de-bruxa [Crinipellis perniciosa Stahel (Singer)]. No presente, a doença ocorre de forma endêmica, podendo agravar a crise da lavoura cacaueira, dificultando ainda mais esta atividade agrícola na região. O fungo penetra na planta por ferimentos nos troncos, necrosando os raios medulares, comprometendo o xilema, causando murcha e secamento da planta, que se processa rapidamente, permanecendo as folhas mortas aderidas à planta por muito tempo, mesmo depois de sua morte (Figura 1). Os sintomas no tronco se expressam em forma de lesões de coloração marrom acastanhada com regiões mais claras, e, estão sempre associadas com galerias feitas pelos insetos Scolitidae (Figura 1a). Essas lesões também podem ocorrer nas raízes (Figura 1b), sendo provável a disseminação do patógeno pelo contato das raízes, como ocorre em outros hospedeiros, tais como: mangueira (Mangifera indica L.), plátano (Platanus spp.), eucalipto (Eucalyptus spp.) e batata-doce (Ipomea batatas L.) (Baker \& Harrington, 2001). O controle mais eficiente e econômico para a murcha-de-Ceratocystis é o uso de material genético resistente. Com este objetivo, na busca de material resistente à doença, utilizou-se o método preconizado por Delgado e Echandi (1965) e modificado por Espinoza (1968) para avaliar a resistência dos clones de cacaueiros do Banco Ativo de Germoplasma (BAG) do Centro de Pesquisas do Cacau, em Ilhéus, Bahia. Nos testes preliminares, foram usados os clones SIC 23, SCA 6, CCN 51, IMC 67 e ICS 1. Os clones SIC 23 e SCA 6 foram usados por serem os padrões de suscetibilidade e resistência, respectivamente, nos testes com C. perniciosa, na Bahia. Os clones IMC 67 e ICS 1, por serem os padrões de suscetibilidade e resistência, respectivamente, e, o clone CCN 51, por ser considerado como intermediário no Equador e nos demais países onde se realizaram testes com $C$. fimbriata (Alarcon, 1994). Os ensaios foram repetidos três vezes e, em cada um, utilizaram-se seis repetições/clone. As concentrações usadas para os testes iniciais foram 30.000, 15.000 e 7.500 UFC/ $\mathrm{ml}$. Segmentos de ramos com aproximadamente $1,5 \mathrm{~cm}$ de diâmetro, correspondentes à região de transição da cor verde da casca para marrom, com tecidos mais lenhosos foram coletados no mesmo dia da inoculação. Seccionaram-se os 
Cacau “Jaca” resistente a Ceratocystis fimbriata na região cacaueira ...

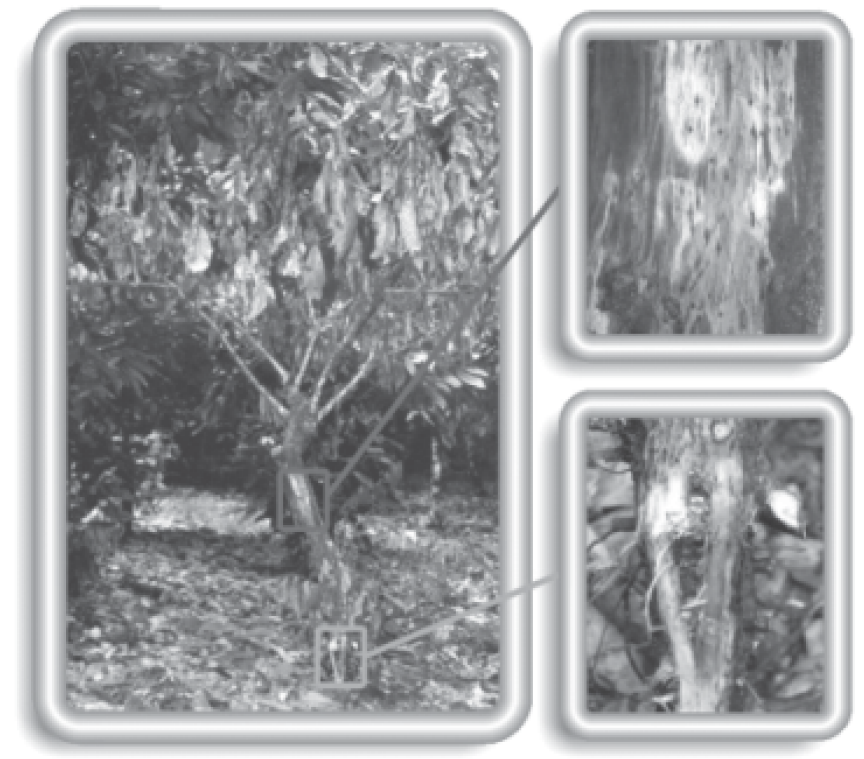

FIG 1 - Sintomas da murcha-de-Ceratocystis em cacaueiro (Theobroma cacao). 1a - Detalhe da lesão de Ceratocystis fimbriata associada com galerias de Scolitidae em tronco de cacaueiro. 2b Detalhe da lesão de coloração púrpura em raízes de cacaueiro.

segmentos dos ramos em fragmentos com $4 \mathrm{~cm}$ de comprimento, que, foram, em seguida, divididos ao meio verticalmente. Depositaram-se 0,45 ml do inóculo com uma pipeta automática sobre a superfície dos tratamentos, espalhando-se o inóculo com auxílio de um pincel. Em seguida, o material inoculado foi colocado em câmara úmida coberta com pano preto para impedir a entrada de luz, permanecendo por quatro dias em uma sala climatizada com temperatura de $25{ }^{\circ} \mathrm{C}$. Após o período de incubação, foi realizada a avaliação do material através de um estereomicroscópio com aumento de 40X, utilizando-se a escala ordinal de notas ( 0 - 4) para quantidade de micélio e peritécios proposta pelos autores do método. A incidência de peritécios foi calculada pela fórmula de Townsend e Heuberger (1943). A alta incidência de peritécios não permitiu distinção entre os clones nas concentrações utilizadas, sugerindo a necessidade de um ajuste na concentração do inóculo. Novos ensaios foram realizados com os cinco clones testados anteriormente, utilizando-se as concentrações de 3.000, 2.000, 1.000, 200 e 100 $\mathrm{UFC} / \mathrm{ml}$. Os clones apresentaram alta incidência de peritécios, como nas avaliações anteriores, em todas as concentrações. Estes resultados indicam que o isolado 2591 da Bahia é muito agressivo e, por isso, optou-se pela menor concentração (100 $\mathrm{UFC} / \mathrm{ml}$ ) para ser utilizada nos ensaios futuros. Foram avaliados 27 clones introduzidos como série internacional, 116 clones do BAG e uma variedade seminal 'Jaca', oriunda da fazenda Nova Vida, região do Cerrado no município de Buerarema, BA. Em todos os testes foram incluídos como padrões os clones ICS1 e IMC 67, suscetível e resistente, respectivamente (Sandoval et al., 1995) e o CCN 51, intermediário (Alarcon, 1994). A avaliação foi feita pelo cálculo da moda dos dados, seguindo a classificação da escala ordinal ( 0 -4) somente para peritécios, embora o micélio, fase vegetativa, também seja uma estrutura infetiva de C. fimbriata. Os clones avaliados da série internacional foram suscetíveis a altamente suscetíveis (Tabela 1). Os clones avaliados do BAG (Tabela 2), na sua maioria, também se apresentaram como suscetíveis a altamente

TABELA 1 - Classificação de 27 clones de cacaueiros (Theobroma cacao) da série internacional, inoculados e avaliados quanto ao crescimento de peritécios de Ceratocystis fimbriata, segundo a escala ordinal de 0 a 4

\begin{tabular}{rlcc}
\hline \hline Classe & Clones & Freqüência & Reação \\
\hline $0-1,0$ & - & - & $\mathrm{R} *$ \\
$1,1-2,0$ & - & - & MR \\
$2,1-3,0$ & AMAZ 15-15, AMAZ 5-2, APA 4, BE 10, CATIE 1000, EET 59, EQX 3360 -3, GU 225, ICS 1, & 18 & $\mathrm{~S}$ \\
& IMC 67, LCTEEN 46, MAN 15-2, MO 20, P7, PA 107, PA 150, SPEC 54 -1, VENC 22-6 & \\
$3,1-4,0$ & GU 175-V, IMC 47, LAF 1, LCTEEN 37 L, Mocorongo, MXC 67, NA 33, PA 120, VENC 4 -4 & 9 & AS \\
\hline
\end{tabular}

*R= resistente; $\mathrm{MR}=$ moderadamente resistente; $\mathrm{S}=$ suscetível; $\mathrm{AS}=$ altamente suscetível

TABELA 2 - Clones de cacaueiros (Theobroma cacao) do Banco Ativo do Germoplasma e uma variedade seminal, inoculados e avaliados quanto ao crescimento de peritécios de Ceratocystis fimbriata, segundo a escala ordinal de 0 a 4

\begin{tabular}{|c|c|c|c|}
\hline Classe & Clones & Freqüência & Reação \\
\hline $0-1,0$ & Jaca; SIAL 577, CB 205 e CB1 205 & 4 & $\mathrm{R}^{*}$ \\
\hline $1,1-2,0$ & SIC 644 e 812 & 2 & MR \\
\hline $2,1-3,0$ & $\begin{array}{l}\text { BE 4; Catongo; CEPEC 10, 11, 12, 13, 14, 16, 18, 19, 38, 42, 74, 86, 89, 90, 515; CCN 34, 51; } \\
\text { CSUL 3, 7, 9; EET 45, 377, 390, 392, 397, 399; EQX 107; IAC 1; ICS 1, 9, 95; IMC 67, 76; } \\
\text { MA16; MO98; NA 33; P4B; RB 36, 39; SCA 6; SIAL 3, 12, 13, 15, 70, 84, 93, 105, 130, 163, } \\
\text { 164, 244, 253, 325, 495, 505, 512, 543, 644, 689, 698; SIC 2, 4, 5, 17, 19, 20, 21, 22, 23, 24, } \\
\text { 250, 328, 329, 433, 439, 662, 680, 7 47, 765, 801, 802, 806, 823, 842, 848, 864, 872, 876, 961; } \\
\text { SGU26; TSA 641, 654, 656, 792; TSH 516, } 565 \text { e } 774\end{array}$ & 100 & $\mathrm{~S}$ \\
\hline $3,1-4,0$ & $\begin{array}{l}\text { CAB5003/23; CCN 10; CEPEC 515; CHUAO 120; MOQ 216; POUND11; SIAL 180, 407, 580, } \\
578 \text { e SIC } 23\end{array}$ & 11 & AS \\
\hline
\end{tabular}


S.D.V.M. Silva et al.

suscetíveis. Os clones SIC 644 e 812 apresentaram-se como moderadamente resistentes. A variedade 'Jaca' mostrou maior resistência, seguida dos clones SIAL 577, CB 205 e CB1 205. Os resultados obtidos demonstraram, mais uma vez, a agressividade do isolado de $C$. fimbriata da Bahia, pois o clone IMC 67, considerado como resistente na literatura, não apresentou o mesmo comportamento. O cacau 'Jaca' é um mutante, originado do Recôncavo baiano e possui esta denominação devido à semelhança de suas folhas arredondadas com as da jaqueira (Artocarpus heterophyllus Lam.). A planta tem porte baixo e possivelmente pode ser recomendada como porta-enxerto nas áreas de renovação de cacaueiros onde ocorre a doença.

\section{AGRADECIMENTOS}

Os autores agradecem aos Dr. José Luiz Bezerra e Dra. Edna Dora M. Newman Luz pela revisão do manuscrito e ao Dr. Luadir Gasparotto pela revisão final e sugestões apresentadas. À técnica agrícola Vírginia Damaceno, pelo apoio nos trabalhos de laboratório.

\section{REFRÊNCIAS BIBLIOGRÁFICAS}

ALARCON, C.R.M. Determinación de resistencia de 250 clones de cacao de origen nacional al ataque de mal de machete. (Tesis Ingeniero Agrónomo). Guayaquil. Universidad Agraria del Ecuador. 1994.

BAKER, C.J. \& HARRINGTON, T.C. Ceratocystis fimbriata. In:
Crop Protection Compedium. Wallingford, UK. CAB International. 2001. (CD version)

BASTOS, C. N \& EVANS, H.C. Ocorrência de Ceratocystis fimbriata Ell. \& Halst. na Amazônia Brasileira. Acta Amazônica 8:543-544. 1978.

BEZERRA, J.L. Ceratocystis fimbriata causing death of budded cocoa seedlings in Bahia, Brazil. Incoped Newsletter 1:6. 1997.

BEZERRA, J.L., ALMEIDA, O.C. de, LUZ, E.D.M.N. \& SILVA, S.D.V. Ocorrência de Ceratocystis fimbriata em clones de cacau no estado da Bahia. Fitopatologia Brasileira 23: 228 (Resumo 117). 1998.

DELGADO, A.J. \& ECHANDI, E. Evaluación de la resistencia de especies y clones de cacao al mal del machete provocado por Ceratocystis fimbriata. Turrialba 15:286-289. 1965.

ESPINOZA, M.A.S. Nuevas Contribuciones al estudio de la resistencia del cacao "Mal-del-Machete" causado por Ceratocystis fimbriata Ellis \& Halsted. (Tesis Ingeniero Agrónomo). Guayaquil. Universidad de Guayaquil. 1968.

HARDY, F. Fungus diseases of cacao and their control. In: Hardy, F. (Ed.) Cacao Manual. Inter- American Institute of Agricultural Sciences, Turrialba, Costa Rica. 1960. pp.242-245.

RORER, J.B. Enfermedades y plagas de cacao en el Ecuador y métodos modernos apropiados al cultivo de cacao. Asociación de Agricultores del Ecuador. 1918. 80p.

SANDOVAL, G.A. de, GRANADA, G.A. \& OCAMPO, F. Evaluación de clones y progenies híbridas de cacao por su reacción a Ceratocystis fimbriata. El Cacaotero Colombiano 39:31-39.1995.

TOWNSEND, G.R. \& HEUBERGER, J.W. Methods for estimating losses caused by diseases in fungicide experiments. The Plant Disease Reporter 27:340-343. 1943. 